\title{
COLEOBROCAS (Insecta: Coleoptera) ASSOCIADAS À MADEIRA DE Tectona grandis LINN. F (Lamiaceae)
}

\author{
Rogério Goularte Moura ${ }^{1}$, Evoneo Berti Filho ${ }^{2}$, Otávio Peres Filho ${ }^{3}$, Alberto Dorval $^{3}$
}

\footnotetext{
' Engenheiro Florestal, Doutorando em Ecologia Aplicada - ESALQ/CENA, CEP 13418-900, Piracicaba-SP, e-mail: rgmoura@gmail.com

${ }_{2}^{2}$ Professor titular, Departamento de Entomologia, Fitopatologia e Zoologia Agrícola, ESALQ/USP, Piracicaba, CEP 13418-900,E-mail:eberti@esalq.usp.br

${ }^{3}$ Professor Associado I, Faculdade de Engenharia Florestal, UFMT, Departamento de Engenharia Florestal, Campus Cuiabá, Cuiabá/MT.
}

\section{RESUMO}

No estado de Mato Grosso, a área plantada possui aproximadamente 43 mil hectares reflorestados com Tectona grandis. A crescente demanda por madeira de reflorestamento vem impulsionando a expansão de novas áreas. Neste contexto, é imprescindível estudos e informações sobre esta cultura no Brasil. Este trabalho teve como objetivo principal identificar as espécies de coleobrocas que atacam a madeira de $T$. grandis com casca e sem casca, em reflorestamento localizado no Município de Rosário Oeste, estado de Mato Grosso. O delineamento experimental adotado foi fatorial $2 \times 4 \mathrm{com}$ dois tratamentos (toretes com casca e toretes sem casca) e quatro tempos de armazenamento (30,60, 90 e 120 dias). Neoclytus pusillus (Cerambycidae) e Xyleborus ferrugineus (Scolytidae) foram as espécies mais importantes nas madeiras com casca e Xyleborus ferrugineus (Scolytidae), Neoclytus pusillus (Cerambycidae), Micrapate sp., Xyloperthella picea e Bostrychopsis uncinata (Bostrichidae) nas madeiras sem casca.

Palavras-chave: Coleobrocas, Tectona grandis, toretes

\section{BORERS (Insecta: Coleoptera) ASSOCIATED TO THE WOOD OF Tectona grandis LINN. F (Lamiaceae)}

\begin{abstract}
This paper evaluates the species of wood borers occurring on cut wood with bark and debarked wood of Tectona grandis. The statistical model was carried out in a completely randomized design. The treatments were defined in a $2 \times 4$ factorial array with two treatment (logs with bark and logs debarked) and four storage times (30,60,90 and 120 days), and the data were analyzed through the statistical program SAS. The most common species in logs with bark were Neoclytus pusillus (Cerambycidae) and Xyleborus ferrugineus (Scolytidae) and the most important ones in debarked logs were Xyleborus ferrugineus (Scolytidae), Neoclytus pusillus (Cerambycidae), Micrapate sp., Xyloperthella picea and Bostrychopsis uncinata (Bostrichidae).
\end{abstract}

Key words: Borers, Tectona grandis, billets 


\section{INTRODUÇÃO}

Tectona grandis Linn. $\mathrm{f}$. (Lamiaceae), conhecida popularmente como teca ou teak (Alemanha, Birmânia, Estados Unidos, Índia, Inglaterra, Siam), teck (França, Itália), ojati (Java), may sak (Laos, Camarões e.Tanzânia), kyum (Burma), tadi, tek, kembal, semarang, jat e sâgwam (Indonésia), djati (Malásia), giathi (Vietnam) e sak (Tailândia) é uma espécie caducifólia de grande porte, com crescimento sazonal determinado, natural das florestas tropicais de monção do sudeste da Ásia (Índia, Myanmar, Tailândia e Laos) onde pode alcançar até 60 metros de altura (Souza; Lorenzi, 2005; Wagenfuhr, 1996; Weaver, 1993).

O cultivo de Tectona grandis tem se mostrado promissor em reflorestamentos no Brasil, principalmente no estado de Mato Grosso, devido às condições edáficas e climáticas favoráveis.

T. grandis, fonte de uma das madeiras tropicais mais valiosas no Mundo, é pouco conhecida no Brasil, tem sido plantada extensamente para a produção de madeira empregada na construção naval, em móveis e carpintaria em geral; além disto, surge como uma alternativa para diminuir a pressão sobre outras espécies florestais de ocorrência natural de grande valor econômico.

As culturas florestais, quando plantadas na forma de povoamentos homogêneos, proporcionam condições favoráveis para a ocorrência de insetos considerados nocivos, devido à simplificação do ecossistema, mudanças ambientais, oferta excessiva de alimento e ineficiência de inimigos naturais, contribuindo para aumento das densidades populacionais com grandes prejuízos às culturas.

São numerosas as publicações que relatam a ocorrência de insetos praga em plantios de $T$. grandis em várias regiões do
Sudeste da Ásia e África, no entanto no Brasil trabalhos científicos abordando tais ocorrências são escassos.

A maioria das pesquisas desenvolvidas com coleobrocas no Brasil é sobre levantamentos populacionais, utilizando-se armadilhas de impacto, empregando como atrativo mais comum o etanol (Carvalho, 1984; Carvalho et al., 1996; Dall'Oglio; Peres Filho, 1997; Flechtmann et al., 1995; Flechtmann; Gaspareto, 1997; Flechtmann; Ottati, 1996; Flechtmann et al., 1999, 2000, 2001; Morales et al., 1999; Murari, 2005).

Poucos são os trabalhos que têm como objetivo relatar os insetos que atacam a madeira no campo, registrar as espécies que ocorrem em madeiras exóticas ou nativas e avaliar a suscetibilidade destas às referidas coleobrocas (Abreu, 1992; Abreu; Bandeira, 1992; Souza et al., 1997).

As coleobrocas são pragas mundialmente conhecidas pelos danos causados às florestas e à madeira de diferentes espécies florestais. Com a expansão das áreas plantadas exclusivamente com T. grandis, em Mato Grosso, os problemas entomológicos poderão constituir-se em fator crítico para o desenvolvimento desta cultura no Estado. Com a finalidade de tornar o controle de pragas mais eficiente, menos oneroso e ecologicamente correto, torna-se necessária a obtenção de informações sobre a biologia e a ecologia dos insetos nocivos, a fim de realizar com eficiência programas de manejo integrado de pragas (MIP). O monitoramento de coleobrocas praga através do uso de armadilhas tronco (toretes) fornece informações importantes para a eficiência do MIP.

O presente trabalho tem por objetivo acrescentar à bibliografia existente informações sobre identificação e ocorrência de coleobrocas que atacam a espécie $T$. grandis, recém-cortada, uma vez que o aumento crescente da área plantada com esta 
espécie acentua a necessidade do conhecimento dos insetos que são ou poderão vir a ser problema para a cultura de T. grandis.

\section{MATERIAL E MÉTODOS}

A pesquisa foi realizada em plantio de Tectona grandis, situado no município de Rosário Oeste, no estado de Mato Grosso, entre $15^{\circ} 05^{\prime} 00^{\prime \prime}$ de latitude Sul e 56 $33^{\circ} 00^{\prime \prime}$ de longitude Oeste e a uma altitude média de 250 metros.

O clima da região é do tipo tropical úmido (Aw), temperaturas elevadas com chuva no verão e seca no inverno (Köppen, 1948). As médias de temperatura dos meses são maiores que $20^{\circ} \mathrm{C}$ e no mês mais frio do ano as mínimas são menores que $18^{\circ} \mathrm{C} \mathrm{com}$ temperatura média anual de $25^{\circ} \mathrm{C}$. A precipitação pluviométrica anual atinge $2.000 \mathrm{~mm}$, concentrando-se nos meses de novembro a abril.

Para acompanhar a sucessão de coleobrocas na madeira de Tectona grandis, foram construídas pilhas de madeira, em talhões com idade variando de quatro a cinco anos de idade e espaçamento de $2 \mathrm{~m} \times 3 \mathrm{~m}$ a $2,5 \mathrm{~m} \times 3 \mathrm{~m}$ metros, submetidos ao primeiro desbaste. Para construção das pilhas foram utilizados toretes, de aproximadamente 1,20 $\mathrm{m}$ de comprimento, retirados dos terços inferior e médio da árvore (Figura 1).

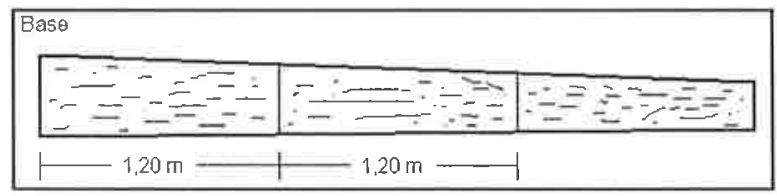

Figura 1. Esquema do comprimento do toretes utilizados na construção das pilhas.

A coleta das amostras foi feita 120 dias após o primeiro desbaste. $\mathrm{O}$ experimento foi organizado segundo delineamento experimental inteiramente casualizado, em esquema de parcelas subdivididas, tendo nas parcelas os tratamentos dispostos em esquema fatorial $2 \times 4$, ou seja, toretes com casca e sem casca e quatro períodos de armazenamento no campo $(30,60,90$ e 120 dias), e nas subparcelas as quatro épocas de coleta (outubro e novembro, fevereiro e agosto).

Cada pilha foi devidamente identificada, sinalizada e composta por 24 toretes, sendo 12 toretes com casca e 12 toretes sem casca.

Decorridos 30, 60, 90 e 120 dias, respectivamente, de armazenamento, as amostras foram selecionadas ao acaso $\mathrm{e}$ seccionadas com motosserra em três discos menores, medindo aproximadamente 15 a 20 centímetros de comprimento, das partes inferior, média e superior do torete. Estes discos foram acondicionados em sacos plásticos com identificação de cada local amostrado e encaminhados ao Laboratório de Proteção Florestal, da Universidade Federal de Mato Grosso (Laproflor-UFMT). No laboratório os toretes foram desdobrados com auxílio de uma marreta de $1 \mathrm{~kg}$ e formão. Os adultos de coleobrocas foram contados, etiquetados e armazenados em coleção entomológica e as larvas e pupas contadas e armazenadas em álcool $80 \%$.

Análise de variância e teste de comparação de médias dos insetos coletados nos tratamentos, com casca e sem casca, e períodos de estocagem foram analisados por Proc GLM e as médias separadas pelo teste Tukey, ao nível de 5\% de significância. Para a normalização dos dados para análise, os valores foram transformados em $\sqrt{x+0,5}$ (ZAR, 1999).

\section{RESULTADOS E DISCUSSÃO}

No total, foram encontrados 1673 indivíduos nas amostras de madeira com casca e sem casca de Tectona grandis, sendo, 1253 larvas, 57 pupas e 363 adultos (Tabela 1). 
Foram identificadas quatro famílias atacando a madeira de Tectona grandis. As famílias Bostrichidae e Scolytidae foram as mais representativas em quantidade de espécie e de gênero. Além das espécies identificadas, constataram-se dois gêneros não identificados ao nível de espécie.

As espécies encontradas foram Bostrychopsis uncinata (Germar,1824); Micrapate germaini (Lesne, 1899); Micrapate sp.; Micrapate sp.1 e Xyloperthella picea (Olivier, 1790) (Bostrichidae); Neoclytus pusillus Laport \& Gory, 1835 (Cerambycidae); Euplatypus parallelus (Fabricius 1801) (Platypodidae); Hypothenemus eruditus Westwood, 1836; Xyleborus affinis Eichhoff, 1867; Xyleborus ferrugineus (Fabricius, 1801) e Xyleborus sp. (Scolytidae).

Dentre as causas de variação avaliadas a época de coleta (E), o tratamento (T), os períodos de armazenamento (P) apresentaram influência direta na quantidade de coleobrocas encontradas nos toretes, enquanto a amostra de cada talhão e interação dupla entre amostra e época de coleta, não apresentaram diferença significativa. Este fato indicou que a amostra e a interação desta com o tempo de coleta não influenciaram, significativamente, na quantidade de coleobrocas coletadas em madeiras com casca e sem casca.

$\mathrm{O}$ teste $\mathrm{F}$ detectou efeitos significativos para as interações duplas entre TxP, ExT, ExP; e tripla entre ExTxP para os fatores de presença e ausência de casca nas amostras de Tectona grandis, período de armazenamento e época de coleta das amostras no campo, indicando que presença ou ausência da casca, períodos de armazenamento e diferentes épocas de coleta influenciam na quantidade média das coleobrocas constatadas no presente estudo. Mais especificamente, a média aritmética do número de coleobrocas aumenta em relação aos períodos de exposição da madeira no campo e diferentes épocas do ano.
Flechtmann (1999), comparando a atratividade de toras com e sem casca de Pinus oocarpa a diferentes espécies de Scolytidae em talhões de pinus no Brasil, também encontrou diferença significativa para os fatores presença de casca, talhão, armadilha, semana e para as interações cascaXarmadilha e cascaXcapturaXtalhão $(\mathrm{p}<0.05)$.

Nas amostras de madeira com casca foram encontrados 1520 indivíduos, dos quais 1183 eram larvas, 56 pupas e 281 adultos. Aos 60 e 90 dias, foram encontradas as maiores quantidades de larvas, e aos 120 dias a maior quantidade de pupas e adultos. As amostras de madeira sem casca apresentaram 153 indivíduos, sendo 70 larvas, uma pupa e 82 adultos (Figura 2).

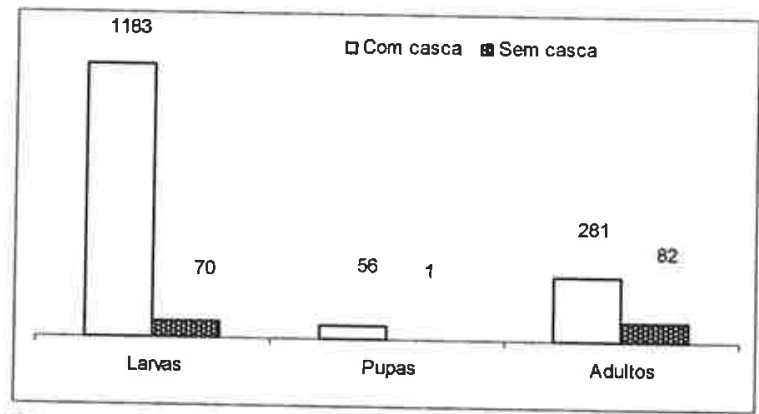

Figura 2. Total de larvas, pupas e adultos encontrados nas amostras com casca e sem casca, de toretes de Tectona grandis, armazenados no campo.

O tempo de armazenamento de 30 dias diferiu de todos os outros períodos testados. Apesar do aumento na quantidade média de coleobrocas com nível máximo de infestação no último período, não foi constatada diferença significativa entre os períodos de 60,90 e 120 dias de armazenamento $(\mathrm{p} \leq 0,05)$ (Tabelas 2$)$.

Foi constatada diferença estatística significativa entre as médias de coleobrocas para os períodos de armazenamento, entre o total encontrado nas diferentes épocas de coleta $\mathrm{e}$ as médias dos tratamentos de madeira com casca e madeira sem casca ( $p$ $\leq 0,05$ ) (Tabela 3). 
As amostras com casca apresentaram maior quantidade de larvas, pupas e adultos comparados às amostras sem casca, nos períodos de 30, 60, 90 e 120 dias de armazenamento no campo (Figura 3). As amostras com casca foram as mais atacadas a partir dos 60 dias, com as infestações aumentando em função do período de estocagem, tendo os maiores níveis ocorridos nos períodos de 60 e 120 dias.

De acordo com Dorval (2002), os danos causados por coleobrocas em toras de

Tabela 1. Quantidade de larvas, pupas e adultos coletados em madeira de Tectona grandis, com casca e sem casca armazenada no campo.

\begin{tabular}{l|c|c|c|c|c|c|c|c|c}
\hline \multicolumn{1}{c|}{ Estágio de } & \multicolumn{2}{|c|}{ Outubro } & \multicolumn{2}{c|}{ Novembro } & \multicolumn{2}{c|}{ Fevereiro } & \multicolumn{2}{c|}{ Agosto } & \multirow{2}{*}{$\Sigma$} \\
\cline { 2 - 10 } desenvolvimento & $\mathrm{C} / \mathrm{C}$ & $\mathrm{S} / \mathrm{C}$ & $\mathrm{C} / \mathrm{C}$ & $\mathrm{S} / \mathrm{C}$ & $\mathrm{C} / \mathrm{C}$ & $\mathrm{S} / \mathrm{C}$ & $\mathrm{C} / \mathrm{C}$ & $\mathrm{S} / \mathrm{C}$ & \\
\hline Larvas & 232 & 18 & 116 & 41 & 70 & 1 & 765 & 10 & 1253 \\
Pupas & 0 & 0 & 7 & 0 & 7 & 0 & 42 & 1 & 57 \\
Adultos & 13 & 1 & 25 & 21 & 228 & 33 & 15 & 27 & 363 \\
\hline Total & 245 & 19 & 148 & 62 & 305 & 34 & 822 & 38 & 1673 \\
\hline
\end{tabular}

$\mathrm{C} / \mathrm{C}=$ madeira com casca (log with bark), $\mathrm{S} / \mathrm{C}=$ madeira sem casca (log debarked)

Tabela 2. Comparação das quantidades médias de coleobrocas nas amostras de madeira de Tectona grandis, com casca e sem casca, durante os períodos de armazenamento e épocas de coleta.

\begin{tabular}{l|ll|lll}
\hline \multicolumn{1}{c|}{ Tempo de armazenamento } & Médias & Épocas & Médias* & Tratamento & Médias* \\
\hline 30 dias & $0,729 \mathrm{a}$ & Agosto & $2,687 \mathrm{a}$ & Com casca & $3,167 \mathrm{a}$ \\
60 dias & $2,237 \mathrm{~b}$ & Outubro & $1,650 \mathrm{ab}$ & Sem casca & $0,319 \mathrm{~b}$ \\
90 dias & $1,758 \mathrm{~b}$ & Novembro & $1,312 \mathrm{~b}$ & & \\
120 dias & $2,246 \mathrm{~b}$ & Fevereiro & $1,059 \mathrm{~b}$ & & \\
\hline
\end{tabular}

*Médias seguidas pela mesma letra, na vertical, não diferem estatisticamente entre si, na vertical, ao nível de $5 \%$ de probabilidade pelo teste Tukey $(\mathrm{p} \leq 0,05)$

Tabela 3 - Comparação do número médio de coleobrocas nas amostras de madeira de Tectona grandis, com casca e sem casca, e épocas de coleta.

\begin{tabular}{lcc}
\hline \multicolumn{1}{c}{ Épocas de coleta } & Madeira sem casca* & Madeira com casca* \\
\hline Outubro & $0,237 \mathrm{a}$ & $3,062 \mathrm{~b}$ \\
Novembro & $0,770 \mathrm{a}$ & $1,850 \mathrm{~b}$ \\
Fevereiro & $0,782 \mathrm{a}$ & $1,092 \mathrm{~b}$ \\
Agosto & $0,775 \mathrm{a}$ & $1,779 \mathrm{~b}$ \\
\hline
\end{tabular}

* Médias seguidas pela mesma letra, na horizontal, não diferem estatisticamente entre si, ao nível de $5 \%$ de probabilidade, pelo teste Tukey $(\mathrm{p} \leq 0,05)$ 
A intensidade de ataque depende do tamanho da população das espécies de coleobrocas no ecossistema florestal e das condições de temperatura para acelerar o processo de fermentação anaeróbica de carboidratos da madeira durante sua deterioração, determinando maiores ou menores danos causados à madeira recémcortada. Aos 30 dias de permanência de amostras de madeira, com casca, recémcortada no ecossistema florestal levam a uma infestação insignificante. Esta baixa infestação é supostamente atribuída às condições desfavoráveis para fermentação rápida e aos baixos níveis populacionais das espécies de coleobrocas. No entanto aos 60 , 90 e 120 dias de permanência das amostras no campo, a infestação aumenta de maneira crescente e se estabiliza (Marques et al., 1990).

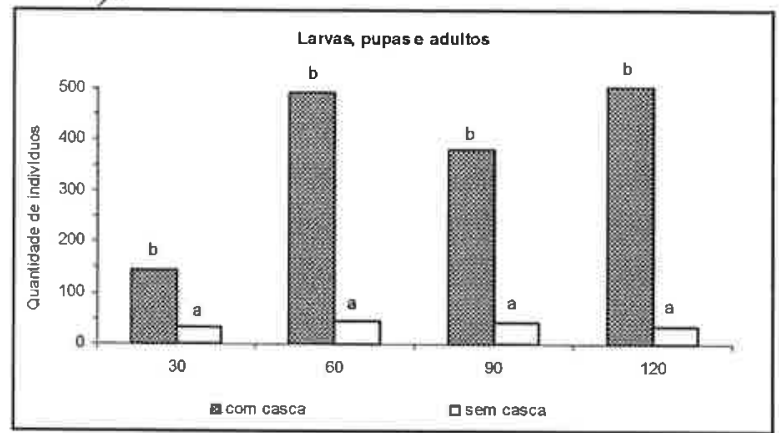

Figura 3. Quantidade de larvas, pupas e adultos encontrados em amostras com casca e sem casca, de Tectona grandis, nos diferentes períodos de armazenamento. Tratamentos com mesma letra não diferem estatisticamente entre si, ao nível de $5 \%$ de probabilidade, pelo teste Tukey $(\mathrm{p} \leq 0,05)$.

O aumento da infestação foi atribuído a dois fatores: a reinfestação e a chegada de um número grande de insetos às amostras.

As madeiras com casca foram as mais atacadas porque inicialmente, as larvas de coleobrocas encontram condições favoráveis ao seu desenvolvimento dentro de galerias superficiais, abertas abaixo da casca. Enquanto nas amostras sem casca, por não apresentarem condições adequadas para a oviposição e manutenção das larvas nos estágios iniciais de desenvolvimento e também pela acelerada perda do teor de umidade, tornam essas amostras menos atrativas para algumas espécies de coleobrocas. No entanto, o empilhamento dos toretes sem casca, pode ter proporcionado condições favoráveis, entre um torete e outro, para a postura e desenvolvimento das larvas encontradas nas amostras sem casca.

A redução da ação dos insetos sobre os toretes de madeira deve-se em grande parte à retirada da casca, que cria condições desfavoráveis tanto para os besouros-dacasca, como para as espécies que fazem oviposição na casca (Costa et al., 1988).

O tempo de permanência das amostras de madeira no interior da floresta pode resultar em baixa quantidade de coleobrocas das famílias Scolytidae e Platypodidae, pois o tempo de permanência pode ser suficiente para a emergência de todos ou da maioria dos indivíduos adultos (Abreu, 1992).

Aos 60 dias de armazenamento foi coletado o maior número de larvas e aos 120 dias de armazenamento as maiores quantidades de adultos nas amostras de madeira com casca (Figura 4).

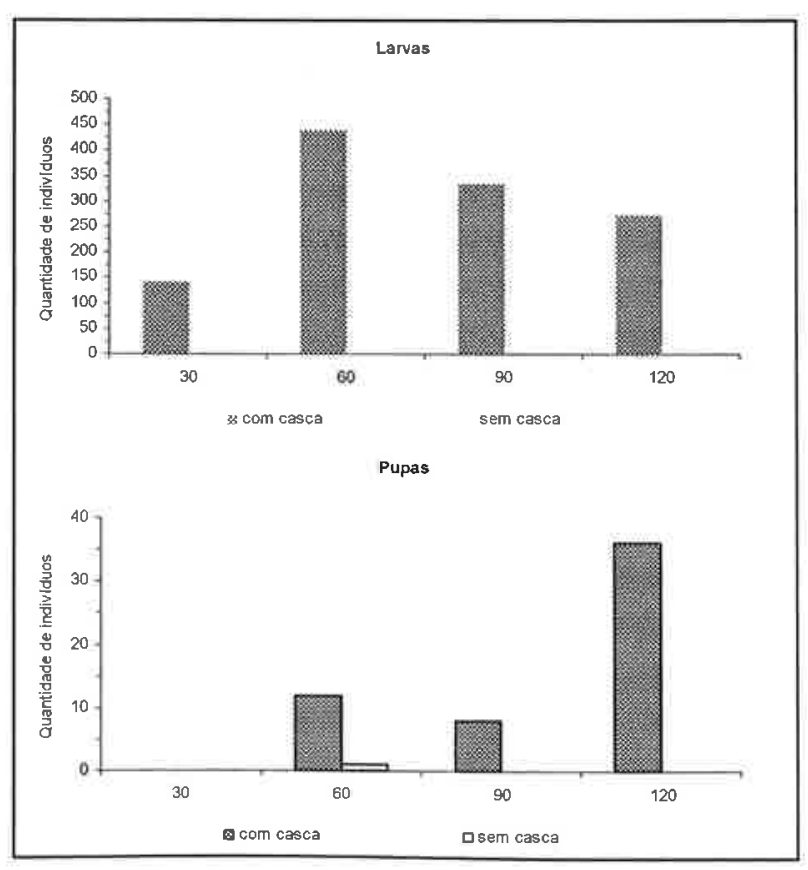




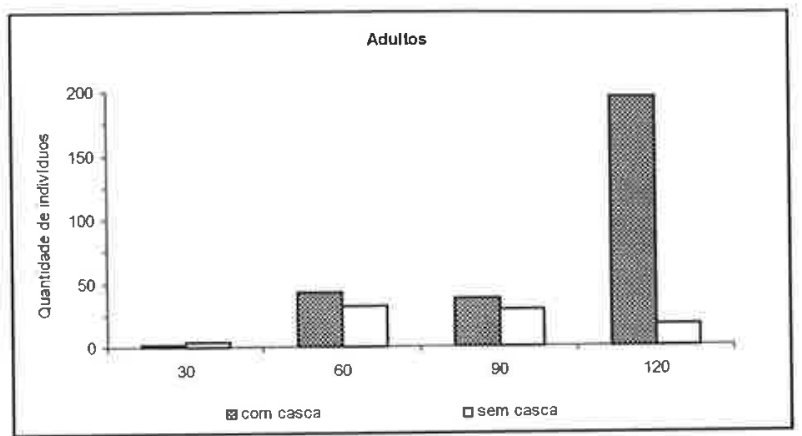

Figura 4. Total de larvas, pupas e adultos encontrados nas amostras com casca e sem casca, de Tectona grandis.

Costa et al. (1988) concluiu que troncos de Mimosa scabrella Bent. com casca, troncos descascados e troncos descascados e tratados com pentaclorofenol não sofrem significativamente a ação do ecossistema que o cerca até os 90 de exposição. No entanto afirmou que a intensidade da ação de organismos do meio é em função do tempo de exposição, principalmente para a madeira com casca.

Neoclytus pusillus (Cerambycidae) e Xyleborus ferrugineus (Scolytidae) foram as espécies mais representativas nas amostras de madeira com casca e sem casca. Espécies da família Bostrichidae ocorreram apenas nas amostras de madeira sem casca.

As fêmeas de Neoclytus pusillus são copuladas por mais de um macho. Seus ovos são brancos, elípticos, medem aproximadamente $1 \mathrm{~mm}$ de comprimento e são colocados em frestas, sob a casca. As primeiras larvas encontradas broqueando a madeira tinham aproximadamente $1 \mathrm{~mm}$ de comprimento e protórax com largura de aproximadamente $0,5 \mathrm{~mm}$. As larvas jovens constroem inicialmente galerias subcorticais, aprofundadas e alargadas posteriormente. As galerias são feitas no sentido longitudinal, medem em média $120 \mathrm{~mm}$ de comprimento $5,0 \mathrm{~mm}$ de largura e $2,0 \mathrm{~mm}$ de profundidade (Penteado-Dias, 1979; Peres Filho et al., 2006).

Marques et al. (1990) reportaram que Xyleborus ferrugineus foi a espécie mais predominante em madeiras armazenadas no interior do povoamento florestal, responsável por $77,4 \%$ do dano total causado às amostras de madeira. E que toda madeira cortada e depositada no interior dos talhões era suscetível à infestação por coleobrocas quando o tempo de permanência foi superior a 30 dias em todos os meses do ano.

O gênero Xyleborus, com o maior número de espécies, é predominante em ambientes naturais e em povoamentos florestais homogêneos (Marques, 1989, Flechtmann, 1995).

Otto et al. (1997) observaram que em toras de Eucalyptus viminalis os maiores niveis de infestações ocorreram nas toras de maior diâmetro, a partir do terceiro mês de estocagem, e que o tempo de estocagem teve maior influência na infestação de madeiras do que a época de estocagem, sendo $95 \%$ dos indivíduos coletados da espécie $X$. ferrugineus.

Os meses com maior precipitação e umidade relativa do ar, concentraram-se no período de dezembro de 2002 a março de 2003. A temperatura média variou de 21,9 ${ }^{\circ} \mathrm{C}$ a $27{ }^{\circ} \mathrm{C}$. Os fatores meteorológicos influenciam os insetos tanto diretamente, como indiretamente. Diretamente afetam o desenvolvimento e o comportamento desses artrópodos, indiretamente afetam sua alimentação, pela quantidade de alimento disponível, regulando as atividades dos insetos, como a dispersão (Silveira Neto et al., 1976).

Além de diminuir ou aumentar o ciclo de vida do inseto a temperatura pode influenciar também na determinação do início do vôo e na sua duração, estímulo para iniciar e permanecer em vôo é governado por uma série de fatores, onde se destacam a luminosidade, a velocidade do vento, a temperatura, a umidade relativa do ar e a precipitação pluvial (Samaniego; Gara, 1970; Flechtmann, 1995).

Zelaya (1985) estudou a influência

da temperatura, umidade relativa $e$ 
precipitação sobre o movimento das populações de Xyleborus spp. e constatou que a temperatura é o parâmetro que mais influenciou no movimento da população de Xyleborus affinis, capturou maior número de indivíduos quando a temperatura variou de 21 a $24^{\circ} \mathrm{C}$ e a umidade relativa esteve em torno de $80 \%$, com uma precipitação superior a $40 \mathrm{~mm}$.

Temperaturas muito altas ou muito baixas causam redução da atividade dos besouros-da-casca ou até mesmo, em alguns casos, a mortalidade destes, quando aquelas ultrapassam certos limites (Wood, 1982).

A maior quantidade de adultos, nas amostras sem casca, foi encontrada durante os periodos com elevada umidade relativa do ar, enquanto nas amostras com casca a maior quantidade foi observada nos períodos de baixa umidade relativa. Segundo Pizzamiglio (1991) o comportamento do inseto é dirigido, principalmente, para evitar a exposição ao calor e a sequia, portanto as condições de alta umidade propiciam ao inseto maior mobilidade no ambiente.

Um dos principais fatores que tem influência sobre a população e a atividade de Scolytidae é a umidade. Para os besourosda-casca influencia na produção de atrativos pela árvore e para os besouros xilomicetófagos, a umidade influencia tanto na invasão como no desenvolvimento $\mathrm{e}$ sobrevivência destes besouros, já que é um fator limitante ao crescimento do fungo. $\mathrm{O}$ fungo requer alta umidade para desenvolvimento, por este motivo, somente toras com alto conteúdo de umidade são atacadas (Pereira, 2006).

Durante os períodos de seca foram coletadas as maiores quantidades de indivíduos de Neoclytus pusillus, Xyloperthella picea e Micrapate sp., diminuindo durante os períodos de chuva nos períodos coletados. Este comportamento foi o inverso para as espécies do gênero Xyleborus.
Flechtmann (1999), comparando a atratividade de toras com e sem casca de Pinus oocarpa, coletou 23 espécies de Scolytidae dentre elas Hypothenemus eruditus. Encontrou grande diversidade e abundância de espécies da tribo Xyleborini e dentre elas as espécies Xyleborus affinis e $X$. ferrugineus. As coletas foram numericamente elevadas nas madeiras sem casca em relação às madeiras com casca. $X$. ferrugineus e Hypothenemus eruditus foram as espécies mais significantes, coletadas nas madeiras com casca e sem casca, respectivamente.

A madeira de $T$. grandis apresenta oleoresina como um de seus constituintes químicos. As oleoresinas possuem componentes derivados de terpenos, como monoterpenos, sexquiterpenos e produtos derivados destes, como monoterpenos oxigenados e produtos originários da fermentação anaeróbica ocorrida na madeira, produzindo álcoois, como por exemplo o etanol que funcionam como atrativos para os besouros-da-casca (Pereira, 2006).

Embora tenham sido encontrados poucos indivíduos de platipodídeos, a espécie Euplatypus parallelus (Sin. Platypus parallelus, $P$. linearis) tem grande importância, principalmente nos trópicos onde sua distribuição é mais regular e largamente distribuída (Abreu, 1992). A não colonização e o baixo número de indivíduos das espécies encontradas podem ser atribuídos ao teor de umidade $\mathrm{e}$ a concentração de substâncias pertencentes às classes das antraquinonas e a tectoquinona, as quais são atribuídas propriedades antifúngicas, bactericidas e repelentes a ataques de alguns insetos, sendo por isso responsabilizada pela durabilidade da madeira (Moreira et. al, 2006).

Dorval (2002) constatou, em discos de madeira de $E$. camaldulensis, $E$. citriodora, E. pellita e E. urophylla, a ocorrência de 11 espécies de coleobrocas, sendo que $N$. pusillus (Cerambycidae), $P$. 
linearis (Platypodidae) e $H$. eruditus (Scolytidae) ocorreram em todas as amostras das quatro espécies de eucaliptos estudadas.

Os coleópteros estão adquirindo importância no ecossistema florestal devido aos danos que vem causando. As famílias da ordem Coleoptera encontradas neste estudo, Scolytidae, Cerambycidae, Platypodidae e Bostrichidae, assim como Scarabaeidae, Chrysomelidae, Buprestidae e Curculionidae abrangem as principais espécies de pragas florestais no Brasil (Berti Filho; Krugner, 1986; Zanuncio et al., 1993).

Além dos cuidados que se deve ter com a estocagem da madeira, deve-se estar atento à composição da vegetação próxima da área de armazenagem, cuidado que pode ser fundamental para evitar o ataque de espécies de Scolytidae, oriundas das áreas com vegetação nativa (Flechtmann; Gaspareto, 1997).

A ocorrência e os danos causados, atualmente no Brasil, pelos coleópteros broqueadores Xyleborus (Scolytidade) e Neoclytus pusillus (Cerambycidae) já foram constatados e citados por muitos pesquisadores brasileiros.

Estima-se que a mortalidade de $60 \%$ de árvores, no mundo, seja causada por representantes da família Scolytidade, conhecidos como besouros-da-ambrósia e besouros-da-casca, além de serem responsáveis por grandes prejuízos financeiros devido aos danos ocasionados à madeira processada e armazenada (Pinto et al., 2004).

No entanto, os besouros-da-ambrósia no Brasil são, geralmente, pragas secundárias, mas em altas populações podem ser prejudiciais para a cultura de $T$. grandis, incluindo danos em árvores recém-cortadas e madeira armazenada e processada.

\section{CONCLUSÕES}

Neoclytus pusillus (Cerambycidae) pode representar uma ameaça constante para os plantios de Tectona grandis.
N. pusillus e Xyleborus ferrugineus (Scolytidae), pela quantidade de espécimes coletados nas amostras com casca e sem casca, representam maior ameaça para $T$. grandis.

As madeiras de $T$. grandis sem casca são menos atacadas do que as madeiras com casca, quando expostas por períodos superiores há 30 dias no campo.

O nível de infestação aumenta com o período de exposição nos plantios de teca.

As amostras de madeiras sem casca, com 30 dias de exposição no campo, apresentam menor intensidade de infestação por coleobrocas.

\section{AGRADECIMENTOS}

Os autores agradecem ao Laboratório de Proteção Florestal da Universidade Federal de Mato Grosso e ao técnico Manoel Lauro da Silva, pelo suporte logístico para a execução deste trabalho, e aos Professores Doutores Ubirajara Martins, do Museu Zoologia da Universidade de São Paulo, e Édson Possidônio Teixeira do Instituto Agronômico de Campinas pela identificação dos insetos.

\section{REFERÊNCIAS BIBLIOGRÁFICAS}

ABREU, R.L.S. Estudo da ocorrência de Scolytidae e Platypodidae em madeiras da Amazônia. Acta Amazônica, Manaus, v. 22, p. 413-420, 1992.

ABREU, R.L.S.; A.G. BANDEIRA. Besouros xilomicetófagos economicamente importantes da região de Balbina, estado do Amazonas, Minas Gerais. Revista Árvore, Viçosa, v. 16, p. 346-356, 1992.

BERTI FILHO, E.; KRUGNER, T.L. Manejo integrado de pragas e doenças em povoamentos de Eucalyptus no Brasil. São Paulo, Silvicultura, v.11, n.41, p.41-43, 1986. 
CARVALHO, A.O.R. Análise faunística de coleópteros coletados em plantas de Eucalyptus urophylla S.T. Blake e Eucalyptus saligna SM. 1984. 105p. Dissertação (Mestrado na área de Entomologia) - Escola Superior de Agricultura Luiz de Queiroz, Universidade de São Paulo, Piracicaba, 1984.

CARVALHO, A.G.; ROCHA, M.P.; SILVA, C.A.M.; LUNZ, A.M. Variação sazonal de Scolytidae (Coleoptera) numa comunidade de floresta natural de Seropédica, RJ. Floresta e Ambiente, Rio de Janeiro, n. 3 p. 9-14, 1996.

COSTA, C.; VANIN, S.A.; CASARICHEN, S.A. Larvas de coleóptera do Brasil. São Paulo: Museu de Zoologia, Universidade de São Paulo. FAPESP, 282 p. 1988.

DALL'OGLIO, O.T.; PERES FILHO, O. Levantamento e flutuação populacional de coleobrocas em plantios homogêneos de seringueira em Itiquira, MT. Scientia Forestalis, Piracicaba, v. 51, p. 49-58, 1997.

DORVAL, A. Levantamento populacional de coleópteros com armadilhas etanólicas em plantios de Eucalyptus spp. em uma área com vegetação de cerrado no município de Cuiabá, estado de Mato Grosso. 2002. 141 p. Tese (Doutorado em Ciências Biológicas) Universidade Federal do Paraná, Curitiba, 2002.

FLECHTMANN, C.A.H.; OTTATI, A.L.T. Scolytidae em área de mata nativa em Selvíria, MS, Brasil. Anais da Sociedade Entomológica do Brasil, Londrina v. 25, n. 2, p. 365-368, 1996.

FLECHTMANN, C.A.H.; OTTATI, A.L.T.; BERISFORD, C.W. Attraction of ambrosia beetles (Coleoptera: Scolytidae) to different tropical pine species in Brazil. Environmental Entomology, College Park, Md., US:
Entomological Society of America n. 28, p. 649- 658, 1999.

FLECHTMANN, C.A.H.; OTTATI, A.L.T.; BERISFORD, C.W. Comparison of four trap types for ambrosia beetles (Coleoptera, Scolytidae) in Brazilian Eucalyptus grandis stands. Journal of Economic Entomology, Lanham, MD, US: Entomological Society of America n. 93, p. 1701-1707, 2000.

FLECHTMANN, C.A.H.; OTTATI, A.L.T.; BERISFORD, C.W. Ambrosia and bark beetles (Scolytidae: Coleoptera) in pine and eucalypt stands in southern Brazil. Forest Ecology and Management, Amsterdam, NL: Elsevier Science Publishers n.142, p. 183-191, 2001.

FLECHTMANN, C.A.H.; COUTO, H.T.Z.; GASPARETO, C.L.; BERTI FILHO, E. Manual de pragas em florestas Scolytidae em reflorestamento com pinheiros tropicais, Piracicaba, Programa Cooperativo de Manejo de Pragas Florestais PCMIOP/IPEF 201 p. 1995.

FLECHTMANN, C.A.H; GASPARETO, C.L.. Scolytidae em pátio de serraria da fábrica Paula Souza (Botucatu/SP) e fazenda Rio Claro (Lençóis Paulista/SP). Scientia Forestalis, Piracicaba, n. 51, p. 61-75, 1997.

KÖPPEN, W. Climatología: con un estudio de los climas de la Terra. México, Fondo Cultural Económico, 479 p. 1948.

MARQUES, E.N. Índices faunísticos e grau de infestação por Scolytidae em madeira de Pinus spp. 1989. 103 p. Tese (Doutorado em Engenharia Florestal) Universidade Federal do Paraná, Curitiba, 1989.

MARQUES, E.N; PEDROSA-MACEDO, J.H.; DIODATO, M.A. Estudio del grado de infestación por Scolytidae en madera cortada. In: IUFRO WORLD 
CONGRESS. Anais... Canadá: IUFRO, 19, v.2, p.270-278, 1990.

MOREIRA, R.Y.O.; ARRUDA, M.S.P.; ARRUDA, A.C.; SANTOS L.S.; MULLER; A.H.; GUILHON; G.M.S.P.; SANTOS; A.S.; TEREZO E. Antraquinonas e naftoquinonas do caule de um espécime de reflorestamento de Tectona grandis (Verbenaceae). Brazilian Journal of Pharmacognosy São Paulo, v. 16 n.3, p. 392-396, Jul - Set, 2006

PENTEADO-DIAS, A.M. Biologia e ontogenia de Neoclytus pusillus (Lap \& Gory) (Coleoptera, Cerambycidae, Cerambycinae, Clytini). Revista Brasileira de Entomologia, Curitiba, v. 23, n. 2, p. 77-83, 1979.

PEREIRA, R.A. Scolytidae em povoamentos de Pinus spp. em Telêmaco Borba -PR. 141 p. Dissertação (Mestrado em Ciências Biológicas - Entomologia) Universidade Federal do Paraná, Curitiba, 2006.

PERES FILHO, O.; DORVAL, A.; BERTI FILHO, E. A entomofauna associada à Teca, Tectona grandis Linn. f. (Verbenaceae), no estado de Mato Grosso. Piracicaba: IPEF, 58 p., 2006.

PINTO, R.; ZANUNCIO JUNIOR, J.S.; ZANUNCIO, T.V.; ZANUNCIO, J.C.; LACERDA, M.C. Coleópteros coletados com armadilhas luminosas em plantio de Eucalyptus urophylla na região amazônica brasileira. Revista Ciência Florestal, Santa Maria, v.14, n. 1, p. 111-119, 2004.

RAO, Y.S. Teak: Its geographical distribution. In: TEAK: INTERNATIONAL TEAK SYMPOSIUM, 1991. Proceedings... Kerala:Kerala Forest Department \& Kerala forest Research Institute, 274 p. 1997.
SAMANIEGO, A.; GARA, R.I. Estúdios sobre la actividad de vuelo y selección de huéspedes por Xyleborus spp. y Platypus spp. (Coleoptera: Scolytidae y Platypodidae). Turrialba, San José, v. 20, n. 4, p. 471-477, 1970.

SILVEIRA NETO, S.; NAKANO, O.; BARBIN, D.; VILLA NOVA, N.A. Manual de ecologia de insetos. São Paulo: Editora Ceres, 420p. 1976.

SOUZA, N.J., MARQUES, E.N.; CORREA, R.M.; OTTO, G.M. Avaliação do grau de infestação de insetos em madeira estocada no Município de São Mateus do Sul, PR. Revista do setor de ciências agrárias, Curitiba, v.16, n. 1/2, p. 63-68, 1997.

SOUZA, V.C., LORENZI, H. Botânica Sistemática-Guia Ilustrado para a identificação das famílias de Angiospermas da flora brasileira, baseado em APG II. São Paulo: Instituto Plantarum de estudos da flora. 640p. 2005.

WAGENFUHR, R. Verbenaceae, Tectona grandis L.f. - Teak. HOLZATLAS 4, neubearberlete Auflage mit Zahbrichen Abbildungen. Fachbuchverlag Leipzig. Germany 668p. 1996.

WEAVER, P.L. Tectona grandis L.f. Teak. New Orleans, LA:US. Department of Agriculture, Forest Service, Southern Forest Experiment Station, 18p. 1993.

WOOD, S.L. The bark and ambrosia beetles of North and Central America (Coleoptera: Scolytidae), a taxonomic monograph. Great Basin Naturalist Memoirs, n. 5, p. 1-1360, 1982.

ZANUNCIO, J.C.; BRAGANÇA, M.A.L.; LARANJEIRO, A.J. FAGUNDES, M. Coleópteros associados à eucaliptocultura nas regiões de São Mateus e Aracruz, Espírito Santo. Revista Ceres. Viçosa, v. 41, n. 22, p. 584-590, 1993. 
ZAR, J.H. Biostatistical Analysis, New Jersey: Prentice-Hall 4th ed, $663 \mathrm{p}$. 1999.

ZELAYA, M. R. M. Observações sobre o comportamento de Xyleborus spp. (Coleoptera: Scolytidae) em florestas de Pinnus spp. na região de Agudos,
Estado de São Paulo. 1985. 88p. Dissertação (Mestrado na área de Entomologia) - Escola Superior de Agricultura Luiz de Queiroz, Universidade de São Paulo, Piracicaba, 1985. 